\title{
The Connectivity of the Winter North Atlantic Oscillation (NAO) and the Summer Okhotsk High
}

\author{
Masayo OGI \\ Frontier Research System for Global Change, Yokohama, Japan \\ Yoshihiro TACHIBANA \\ Liberal Arts Education Center, Tokai University, Hiratsuka, Japan \\ International Arctic Research Center, Frontier Research System for Global Change, Yokohama, Japan \\ and \\ Koji YAMAZAKI \\ Graduate School of Environmental Earth Science, Hokkaido University, Sapporo, Japan \\ International Arctic Research Center, Frontier Research System for Global Change, Yokohama, Japan \\ (Manuscript received 25 June 2003, in final form 25 February 2004)
}

\begin{abstract}
We statistically investigated winter-summer climatic connectivity between the winter North Atlantic Oscillation (NAO), and the summer Okhotsk High. We found that the winter NAO persistently influences the surface air temperature, snow cover over the Eurasia continent, sea ice and SST around the Barents Sea region from winter to summer. The warm air temperature anomalies in East Siberia make a preferable condition for upper-level blocking. Warm signals around the Barents Sea region excite the Rossby wave propagating toward the Sea of Okhotsk. In addition, regional persistency of the wintertime local phenomena, and their possible influence on the summertime Okhotsk High is examined. The negative phase of the winter NAO is related to the winter and spring heavy sea ice in the Sea of Okhotsk. The heavy spring sea ice in the Sea of Okhotsk brings about the cold SST around the Sea of Okhotsk. However, since the Okhotsk High does not have correlation with the SST around the Sea of Okhotsk in the previous month, the local connection of the sea ice in the Sea of Okhotsk with the summer Okhotsk High is unlikely. Associated with an enhanced Okhotsk High, cold SST anomalies appear to the east of Japan. This cold SST anomaly is a response to the cold air advection associated with the Okhotsk High. We suggest that the winter NAO remotely regulates both the winter sea ice, and the summer Okhotsk High.
\end{abstract}

\section{Introduction}

In early summer, the climate around the Sea of Okhotsk is characterized by the occurrence

Corresponding author: Masayo Ogi, Frontier Research System for Global Change, Yokohama 2360001, Japan.

E-mail: masayo.ogi@jamstec.go.jp

(C) 2004, Meteorological Society of Japan of the Okhotsk High, and its interannual variability is very large. The occurrence of the Okhotsk High brings about thick fog and cool wet weather conditions in northern Japan (Kudoh 1984; Kato 1985; Kawano 1989). In addition, the Okhotsk High regulates the Asian summer monsoon and plays an important role in influencing the associated Baiu/Meiyu stationary front (e.g., Ninomiya and Mizuno 1985, 
1987; Wang 1992). Therefore, understanding the interannual variation of the Okhotsk High is important for not only regional-scale, but also large-scale climates. Recently, Ogi et al. (2003a, 2003b) found that summertime largescale atmospheric circulations are connected to the North Atlantic Oscillation (NAO) of the previous winter. They pointed out that in the year of a positive phase of the winter NAO, the summertime $500 \mathrm{hPa}$ geopotential height anomaly field in the mid-latitudes is overall positive, especially over the Sea of Okhotsk, central Siberia, the British Isles and North America. Their result suggests the existence of a winter-summer large-scale remote connection with the climate around the Sea of Okhotsk. In their study, however, the relation of the winter NAO to the atmosphere over the Sea of Okhotsk is barely mentioned, because the scope of the study did not concentrate on the Sea of Okhotsk, but instead addressed hemispheric scale atmosphere. A study on the relationship between the sea ice in the Sea of Okhotsk and the Amur River discharge conducted by Ogi et al. (2001), also suggested the existence of the winter-to-summer connection. They showed that the summertime river discharge, which is influenced by summertime atmospheric patterns, is closely related to the wintertime sea-ice variation, which is related to the wintertime atmosphere. This good correlation between the winter ice and the summer river discharge might be due to the atmospheric winter-to-summer connection.

In the present paper, large-scale winterto-summer atmospheric connectivity, influencing the summertime climate around the Sea of Okhtosk is investigated. To deduce this, correlation and linear regression analyses among the atmospheric circulation, SST, sea ice and snow cover from winter through summer, are applied. In addition, regional persistency of the wintertime local phenomena, such as sea ice and SST around the Sea of Okhotsk, and their possible influence on the summertime Okhotsk High is examined.

\section{Data}

Atmospheric data used in this study are from the National Center for Environmental Prediction/National Center for Atmospheric Research (NCEP/NCAR) monthly mean re- analysis dataset, with a $2.5^{\circ} \times 2.5^{\circ}$ regular latitude-longitude grid (Kalnay et al. 1996; Kistler et al. 2001). The monthly mean sea-ice area and SST in the Arctic Ocean, issued by the Global Sea Ice Coverage and Sea Surface Temperature Data (GISST2.3b) with a $1^{\circ} \times 1^{\circ}$ resolution from 1971 to 2000 , are also used. The snow cover frequency is based on the digital NOAA-NESDIS Weekly Northern Hemisphere Snow Charts from 1971 to 1995 , compiled by Robinson et al. (1993). The NAO index is defined as the SLP difference between Stykkisholmur, Iceland and Ponta Delgada, Azores by Hurrell (1995) from 1971 to 2000. The Okhotsk High index is apply to the areaaveraged monthly sea level pressure (SLP) within the Sea of Okhotsk. The averaging area is from $50-60^{\circ} \mathrm{N}$ through $140-160^{\circ} \mathrm{E}$. The sea ice data of the Sea of Okhotsk, issued by the Japan Meteorological Agency (JMA) from 1971 to 2000 are used. Information about the JMA data is mentioned in Yamazaki (2000) in detail. The JMA data is manually analyzed every 5 days, using the GMS, the NOAA satellite images, the SSM/I data and other available observations.

\section{The remote connection between winter NAO and summer Okhotsk High}

To confirm NAO's inter-seasonal connection, we calculated the regression/correlation coefficient of the SLP field in June, with the NAO index in January (Fig. 1). A high positive correlation/regression area over the Sea of Okhotsk is obvious in this figure. This NAO's inter-seasonal connection with the summertime atmospheric pattern is in agreement with Ogi et al. (2003a, 2003b), in which the wintertime NAO is related to the summertime atmospheric annular pattern in the troposphere. They showed that the wintertime NAO is related to the summertime hemispheric northsouth geopotential seesaw between the Arctic and circumpolar ring, in which strong signatures are in the Sea of Okhotsk, central Siberia and the British Isles.

Ogi et al. (2003a) pointed out that the winter NAO index does not have a significant autocorrelation after March. The signal of the winter NAO can be memorized in the snow-cover, sea ice and surface oceans, and the anomalies 


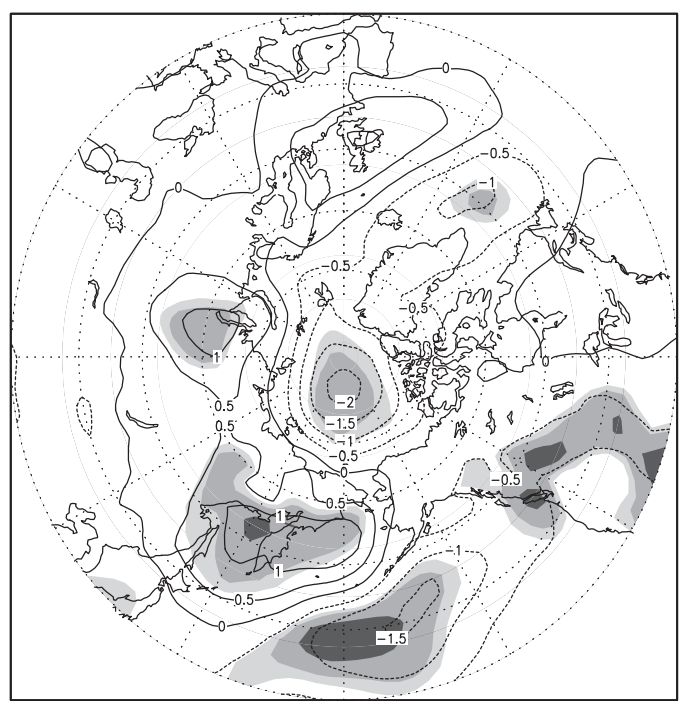

Fig. 1. The maps of the correlation and regression coefficients of the monthly mean sea level pressure (SLP) in June, with the NAO in January from 1971 through 2000. Areas of light, middle light, and heavy shading indicate that correlation coefficients exceed the $90 \%$, $95 \%, 99 \%$ confidence levels, respectively. The confidence limit is based on a twosided Student's $t$-test. The contour interval is $0.5 \mathrm{hPa}$.

memorized in them, then influence the summertime atmospheric circulations. To determine the ground hydrological and oceanic processes related to both the summertime Okhotsk High and the wintertime NAO, we calculated the correlation coefficients of variables related to the surface processes.

The correlation/regression of the surface temperature at 2-m in June correlating with the winter NAO (Fig. 2a), displays large values over the mid-latitudes over northern Eurasia and northern North America, especially over central Siberia and the northern Sea of Okhotsk. Figure 2b shows the correlation coefficients of the NAO in January, with the SST, sea-ice, and snow cover in June. The warm color in the figure denotes a warmer SST, less sea-ice and less snow cover for the positive NAO index in winter. The snow cover and surface air temperature over eastern Siberia show significant correlations with the NAO in January. The positive NAO in January is associated with less snow and warm surface air temperature over eastern Siberia in June, which tends to reduce the upper-level westerly over the Sea of Okhotsk through thermal wind relationship and produce positive height anomalies there (see Fig. 2 in Ogi et al. 2003a). In addition, the sea-ice over the Barents Sea is negatively correlated with the NAO in January, and the SSTs over the Barents Sea are also positively correlated with the NAO in January. Fig. 2 possibly indicates that the influence of the winter NAO is memorized in these regions, and that some of these memorized anomalies affect the interannual variation of the Okhotsk High.

To illustrate the inter-seasonal persistent signal in the surface temperature anomaly that is influenced by the winter NAO, we show the inter-seasonal variation of the surface temperature regressed with the winter NAO. Figure 3 shows the lag correlation of the surface temperature at $2-\mathrm{m}$ along the latitude of $70^{\circ} \mathrm{N}$ with the NAO index in January. When the NAO is in a positive phase, the Eurasia continent is, as a whole, persistently warmer through March. This wintertime warm temperature over Eurasia is in agreement with previous studies (e.g., Hurrell 1996; Xie et al. 1999; Wu and Wang 2002; Ogi et al. 2003a, 2003b). Moreover, the warm anomaly persists through spring around the Atlantic region. Especially over the Barents Sea $\left(20^{\circ} \mathrm{E}-60^{\circ} \mathrm{E}\right)$ region, warmer anomalies persist until July. Wu and Wang (2002) pointed out that the winter $\mathrm{AO}$ influences the winter surface air temperature in the high latitudes of the Asian Continent and the Barents Sea. In addition, this persistency is in agreement with the persistency of other surface processes shown by Ogi et al. (2003a), who showed that anomalies of the Eurasian snow cover, Barents SST and Barents sea ice, persist from spring through summer.

Figure 4 shows the correlation/regression coefficient map, between the winter NAO index and the geopotential height at $500 \mathrm{hPa}$ in June. Over the Sea of Okhotsk region, a positive high correlation, which corresponds to the Okhotsk High, is obvious, and a wave-like pattern from central Siberia to eastern Siberia can be seen. Wang (1992), and Wang and Yasunari (1994) pointed out that eastward Rossby wave propagation from the west of East Siberia, might be one of the possible factors for forming the 


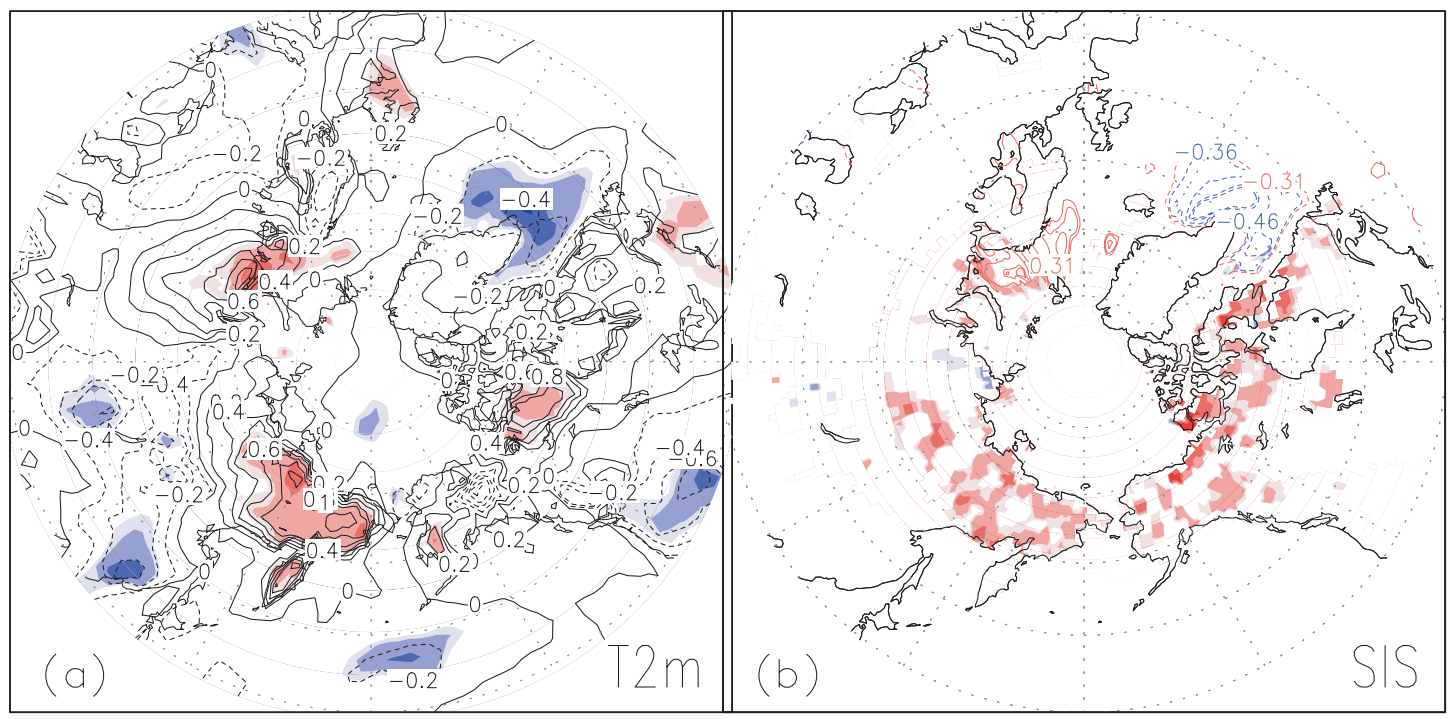

Fig. 2. (a) The correlation and the regression coefficients of the surface temperature at 2-m in June with the NAO index in January. The shadings are the same as those in Fig. 1. (b) Correlation and regression coefficients of the SST, sea ice and snow cover in June with the NAO index in January. Contours over oceans are correlations of the SST. Solid (red) and broken (blue) lines represent the positive and negative correlations, respectively. The shadings over oceans are correlations of the sea-ice. The shadings over land are correlations of snow cover. The denotations of the shading areas are reversed to Fig. 1 (red denotes negative, blue denotes positive).

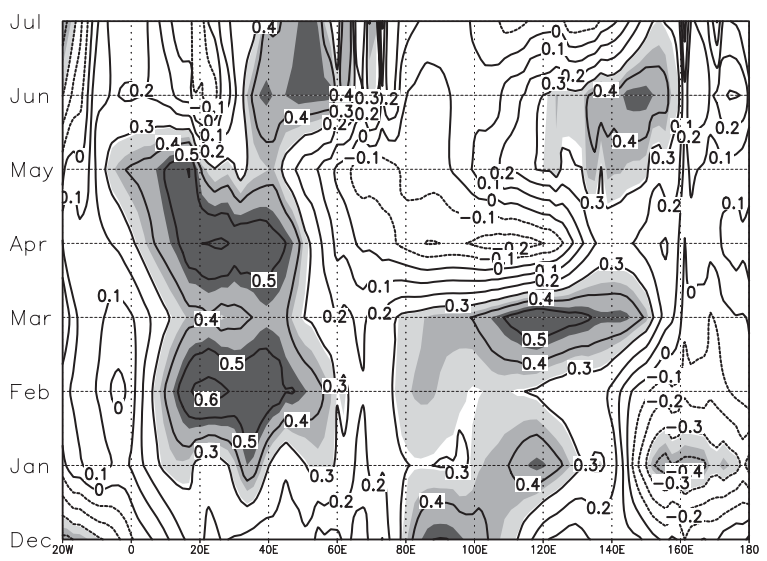

Fig. 3. Lag correlation of the monthly surface temperature at $2-\mathrm{m}$ along the latitude of $70^{\circ} \mathrm{N}$ with the $\mathrm{NAO}$ index in January. The shadings are the same as those in Fig. 1.

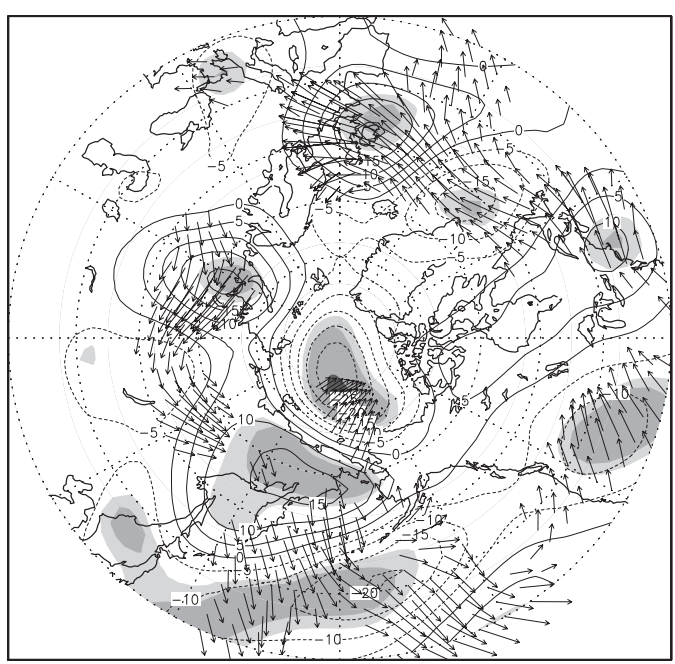

Fig. 4. The correlation/regression of the monthly geopotential height at $500 \mathrm{hPa}$ in June, with the NAO index in January. Arrows indicate the wave-activity flux $\left(\mathrm{m}^{2} \mathrm{~s}^{-2}\right)$ at $300 \mathrm{hPa}$, formulated by Takaya and Nakamura (1997, 2001). The shadings are the same as those in Fig. 1. 
Okhotsk High. However, they did not clearly point out the source region of the Rossby waves. The wave-like pattern in Fig. 4 suggests that the Rossby wave excited over central Siberia propagates toward the Sea of Okhotsk, and possibly influences the atmospheric circulation around the Sea of Okhotsk. Arrows superimposed in Fig. 4 are the wave activity flux formulated by Takaya and Nakamura (1997, 2001 ) at the $300-\mathrm{hPa}$ level. The arrows clearly exhibit the eastward flux mainly emanating from the southern coast of the Barents Sea, in which the sea ice, SST and surface temperature anomalies are significant (see Fig. 2) toward the north of the Sea of Okhotsk. This wave activity flux pattern suggests that the surface anomalies around the Barents Sea, which are attributed to the variation of the winter NAO, excite the Rossby wave propagating in a downwind direction toward the Sea of Okhotsk, and then enhance the Okhotsk High. From the Okhtosk region, the wave propagates to the North Pacific and the Arctic, generating negative anomalies. The negative anomalies in the North Pacific are located at the eastward extension of the Baiu frontal zone.

\section{A possibility of regional sea ice influence on the Okhotsk High}

Our main findings is that the wintertime NAO has a linkage to the following summertime Okhotsk High. We suggest that the signal of the wintertime NAO is memorized in the snow over Eurasia and the sea ice, SST over the Barents Sea. Along with this remote influence, the sea ice in the Sea of Okhotsk may locally influence the atmosphere around the Sea of Okhotsk, through the summer SST in, and around, the Sea of Okhotsk. The Sea of Okhotsk is covered by sea ice from November through May, and the interannual variability of the Okhotsk sea ice is quite large (e.g., Tachibana et al. 1996). Many previous studies on the wintertime environmental atmospheric conditions have pointed out that the winter sea-ice in the Sea of Okhotsk, is associated with wintertime large-scale atmospheric anomalies (e.g., Cavalieri and Parkinson 1987; Parkinson 1990; Tachibana et al. 1996). Yamazaki (2000) pointed out that the winter NAO, and the sea ice extent in the Sea of Okhotsk, has a negative correlation of -0.46 . On the other hand,
Table 1. The auto-correlation coefficients of the sea ice in the Sea of Okhotsk.

\begin{tabular}{l|llllll}
\hline & Dec & Jan & Feb & Mar & Apr & May \\
\hline Dec & 1.0 & 0.70 & 0.44 & 0.24 & 0.47 & 0.55 \\
Jan & & 1.0 & 0.76 & 0.32 & 0.46 & 0.55 \\
Feb & & & 1.0 & 0.65 & 0.57 & 0.44 \\
Mar & & & & 1.0 & 0.74 & 0.51 \\
Apr & & & & & 1.0 & 0.81 \\
May & & & & & & 1.0
\end{tabular}

the extreme change of the sea-ice is suggested to influence large-scale atmosphere as well as local atmosphere (Honda et al. 1996, 1999). In addition, because the auto-correlation of the sea-ice has a large persistency from winter to spring (Yamazaki 2000), the spring sea-ice, as well as the winter sea-ice, must be regulated by wintertime atmospheric patterns. Table 1 shows the auto-correlation of the sea-ice in the Sea of Okhotsk from December through May. The correlation coefficients among all the months are positive. Due to the absorption of the latent heat during melting periods, springtime ice may prevent the SST from rising. Therefore, there is the possibility that the local variations of the SST in the Sea of Okhotsk in late spring and early summer may influence the Okhotsk High. To examine the relationship among the interannual variations of the sea ice in the Sea of Okhotsk in spring (April-May), the monthly mean SST and the SLP from spring to summer. We calculate the correlation/ regressions coefficients among them. First, the relationship between the spring (April-May) sea ice in the Sea of Okhotsk, and the SST from April to June is shown in Figs. 5a, 5b, and 5c. The simultaneous correlation/regression for April and May (Figs. 5a and 5b) shows that the regression coefficients in the southeast Sea of Okhotsk, northern North Pacific and the Bering Sea are overall negative, and that the correlation coefficients in these areas exceed the statistically significant level of 99\%. The large negative correlation area in the northern North Pacific, moreover, persists through June (Fig. 5c). This high correlation/regression area for July, however, becomes narrower (not shown). This represents the fact that after the heavy spring ice cover in the Sea of Okhotsk, the negative SST anomaly in the northwestern 

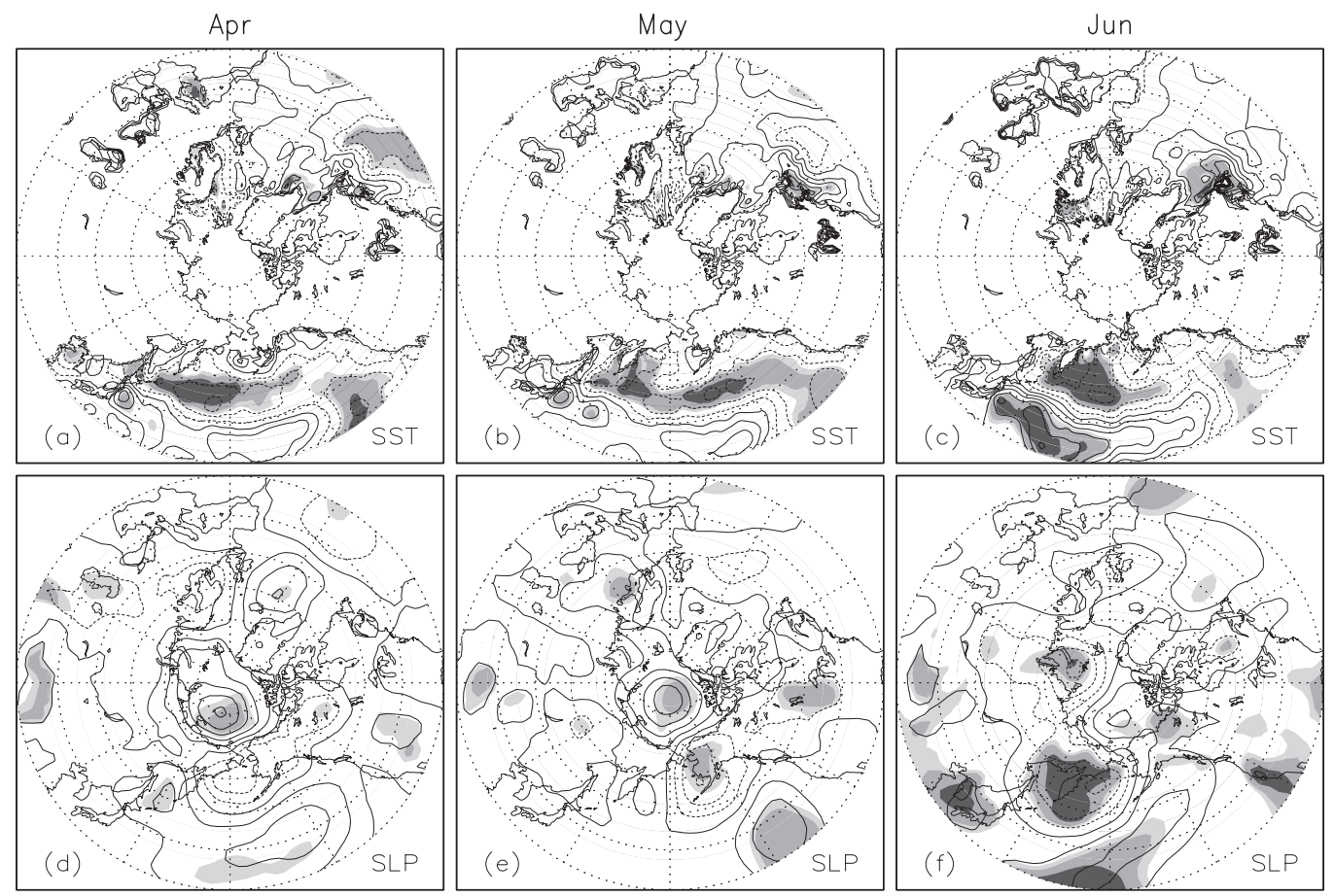

Fig. 5. The maps of the correlation and regression coefficients of the monthly mean sea surface temperature (SST) (Fig. 5a: April, 5b: May, 5c: June), and the monthly mean sea level pressure (SLP) (Fig. 5d, 5e, 5f), with the sea-ice extent index averaged from April through May over the Okhotsk Sea (OSI) from 1971 through 2000. The shadings are the same as those in Fig. 1. The contour interval is $0.1 \mathrm{~K}$ in Fig. 5a, 5b, 5c and $0.5 \mathrm{hPa}$ in Fig. 5d, 5e, 5f.

North Pacific persists through the early summer. However, no persistent signal of the SST can be seen within the Sea of Okhotsk. In Fig. $5 c$, the positive SST anomalies east of Japan are enhanced in June, which can be interpreted as the effect of the Okhotsk High, and will be discussed later.

Figures $5 \mathrm{~d}, 5 \mathrm{e}$ and $5 \mathrm{f}$ show the correlation/ regression of the SLP from April to June with the spring sea ice in the Sea of Okhotsk. Patterns in April (Fig. 5d) show a positive correlation over the Sea of Okhotsk, whose statistical significance is, however, weak. In May (Fig. 5e), no significant correlation signal can be seen in and around the Sea of Okhotsk. However, in June, negative correlation/regression coefficients over and around the Sea of Okhotsk are significantly high, and the high correlation area covers most of the Sea of Okhotsk, and the western Bering Sea. In July, the statistically significant area mostly disappears (not shown). The results shown in Fig. 5 indicate that when the sea ice in the Sea of Okhotsk is heavier than normal, the persistency of the SST in the Sea of Okhotsk is small, but in contrast, in the northwestern North Pacific, the persistency is quite large.

In addition, we examine the correlation coefficient between the surface temperature at $2-\mathrm{m}$, the SST and the Okhotsk High index, which is defined as the area-averaged SLP over the region $50-60^{\circ} \mathrm{N}, 140-160^{\circ} \mathrm{E}$ in June, are shown in Fig. 6. The contour lines over the ocean in the figure denote SST correlation with the Okhotsk High, the shadings over the ocean are sea ice correlation with the Okhotsk High, and the contour lines over the land are the surface temperature correlation with the Okhotsk High. The simultaneous correlation of the surface temperature with the Okhotsk High (Figure $6 \mathrm{~b}$ ), shows a positive correlation area over the land north of the Sea of Okhotsk, and the land south of the Barents Sea. A negative correlation of sea ice is found in the Barents 

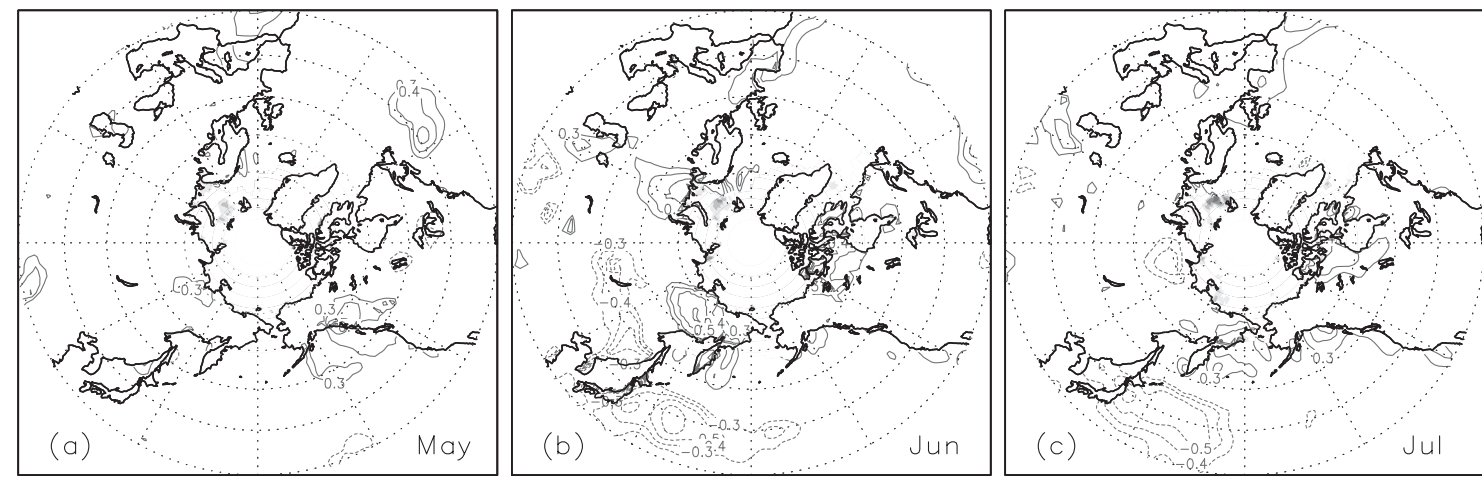

Fig. 6. The correlation coefficients between the Okhotsk High index $\left(50-60^{\circ} \mathrm{N}, 140-160^{\circ} \mathrm{E}\right)$ in June and the SST and the surface temperature at 2-m in (a) May (b) June (c) July. Contours over the ocean are SST correlation with the Okhotsk High, the shadings over the ocean are sea ice negative correlation with the Okhotsk High, and the contour lines over land are the surface temperature at 2-m correlation with the Okhotsk High. Contour and shading indicate correlations of $r>0.3$. The denotations of the shading areas are reversed to Fig. 1 (red denotes negative, blue denotes positive).

Sea. The positive correlation over the northern Eurasia area is the same areas as those of the positive relationship between the surface temperature in June, and the winter NAO index (Fig. 2a). These results further support that the winter NAO influences surface temperature and snow cover, and these memorized anomalies affect the Okhotsk High. An elongated negative area is seen from Lake Baikal to the northwestern Pacific. The strong Okhotsk High is associated with warmer surface air temperatures to the north and colder temperatures to the south. This meridional gradient of low-level temperatures implies a weakening of upperlevel westerly flow through the thermal wind relationship, and it is consistent with the fact that the Okhotsk High is usually accompanied by an upper level blocking.

In the northwestern Pacific, although the negative values persist through the following month (July), they do not appear in the previous month (May). This fact suggests that the SST anomalies in the northwestern Pacific is not a cause of the Okhotsk High, rather they are generated by the atmospheric circulation anomalies associated with the strong Okhotsk High. The northerly cold air advection to the east and south of the Okhotsk High, may cause the cold SST anomalies in the northwestern part of the North Pacific. Arrows in Fig. 7 show the regressed surface wind at $10-\mathrm{m}$ in June with the Okhotsk High index, and contours in Fig. 7 show the climatology of the surface air temperature at 2-m in June. The cold advection is obvious over the negative SST region, which lies to the east of Japan shown in Fig. 6(b). Figures 8(a) and (b) respectively show the regressions of the latent and sensible heat fluxes in June, with the Okhotsk High index in June. Both are positive in the region to the east of Japan, indicating that the ocean loses heat through sensible and latent heat fluxes. These results are consistent with the notion that the northerly cold wind associated with the Okhotsk High, generates the cold SST in

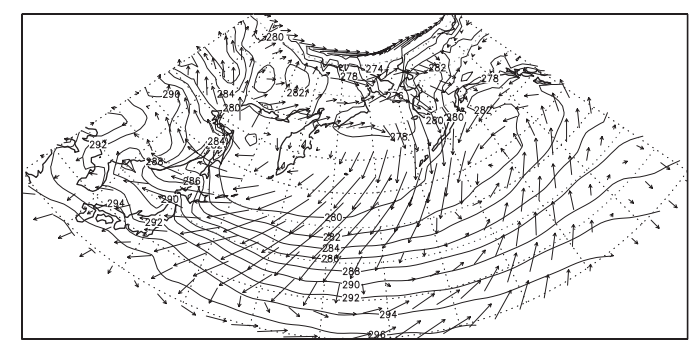

Fig. 7. The regression coefficients 'of the surface wind at $10-\mathrm{m}$ in June with the Okhotsk High index in June (Arrows). The contours are the climatology of the surface air temperature at 2-m in June, from 1971 through 2002. 

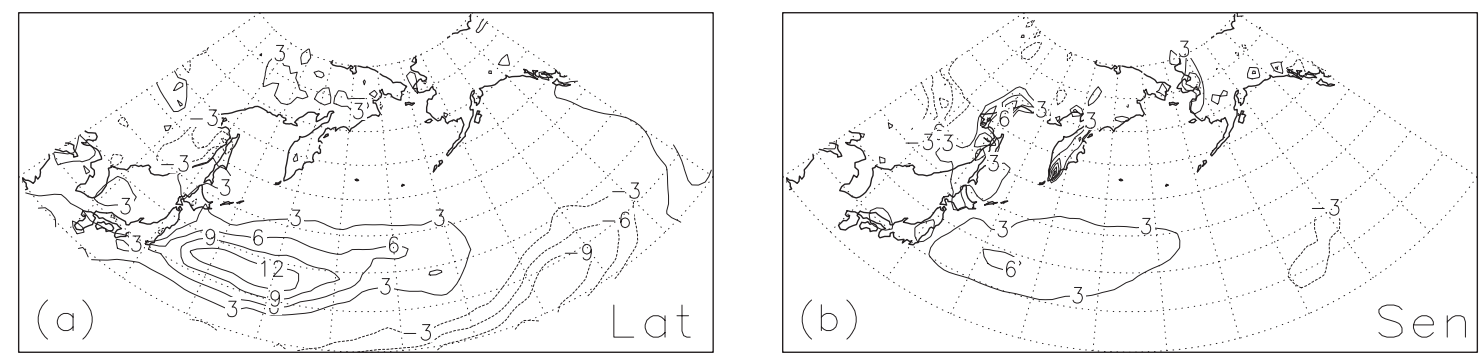

Fig. 8. The regression coefficients between the Okhotsk High index in June and (a) the Latent heat flux, (b) the Sensible heat flux $\left(\mathrm{Wm}^{-2}\right)$.

the region to the east of Japan. In this respect, the SST anomalies associated with spring sea ice in the Sea of Okhotsk (Fig. 5a, 5b) do not affect the formation of the Okhotsk High. Rather, the Okhotsk High causes the SST anomalies in the region to the east of Japan. In Fig. 5c, which shows correlations between spring sea-ice and SST, the positive SST anomalies east of Japan are enhanced in June. This can also be interpreted as the effect of the Okhotsk High.

\section{Conclusions}

This study has examined connectivity between the wintertime NAO and the summertime Okhotsk High in the interannual time scale. When the NAO in January is in a positive (negative) phase, the Okhotsk High in June is stronger (weaker) than normal. The wintertime NAO leaves strong memories in snow in Eurasia, in the sea ice and the SST over the Barents Sea. These strong memories persist through summer. In addition, the memorized surface anomalies excite the stationary Rossby wave in the Barents region, and propagate eastward to the Sea of Okhotsk. As a result, the wintertime NAO has good connectivity with the summertime Okhotsk High in the interannual time scale.

From the local inter-seasonal point of view, springtime anomalous light coverage of the sea ice over the Okhotsk Sea is connected with the strong Okhotsk High. The Okhotsk high correlates the SST in the Barents Sea, the surface temperature of the southern continent of the Barents Sea and the northern continent of the Sea of Okhotsk. The Barents area is influenced by the winter NAO influence. The good correlation between the springtime sea ice in the Sea of Okhotsk, and the summertime Okhotsk High, is not the direct physical relation. Both variations are caused by the winter NAO.

Our findings suggest that the winter NAO is a predictor for the summertime Okhotsk High, which strongly influences the summertime Asian monsoon (e.g., Ninomiya and Mizuno 1987). Therefore, the finding in this paper has an important implication for forecasting the summertime East Asia climate.

\section{Acknowledgments}

We would like to thank Dr. Honda in Frontier Research System for valuable discussions and for his advice on the usage of the programs. We also have had fruitful discussion with Dr. Takeuchi in Frontier, Dr. Ukita in Columbia Univ. and Dr. Tanimoto in Hokkaido Univ., who provided perceptive insight into the ice, SST and the ocean variations. Dr. Minobe in Hokkaido Univ. and the reviewers provided helpful comments and suggestions. Furthermore, we thank Mr. Kaneko in JMA who willingly provided us the sea-ice data over the OS. The Grid Analysis and Display System (GrADS) was used for drawing the figures.

\section{References}

Cavalieri, D.J. and C.L. Parkinson, 1987: On the relationship between atmospheric circulation and fluctuations in the sea ice extents of the Bering and Okhotsk seas. J. Geophys. Res., 92, 7141-7162.

Honda, M., K. Yamazaki, Y. Tachibana, and K. Takeuchi, 1996: Influence of Okhotsk sea-ice extent on atmospheric circulation. Geophys. Res. Lett, 23, 3595-3598. 
H. Nakamura, and K. Takeuchi, 1999: Dynamic and thermodynamic characteristics of atmospheric response to anomalous sea-ice extent in the Sea of Okhotsk. J. Climate, 12, 3347-3358.

Hurrel, J.W., 1995: Decadal trends in the North Atlantic Oscillation: Regional temperatures and precipitation. Science, 269, 676-679.

- , 1996: Influence of variations in extratropical wintertime teleconnections on Northern Hemisphere temperature. Geophys. Res. Lett., 23, 665-668.

Kalnay, E., M. Kanamitsu, R. Kistler, W. Collins, D. Deaven, L. Gandin, M. Iredell, S. Saha, G. White, J. Woollen, Y. Zhu, M. Chelliah, W. Ebisuzaki, W. Higgins, J. Janowiak, K.C. Mo, C. Ropelewski, J. Wang, A. Leetmaa, R. Reynolds, Roy Jenne, and Dennis Joseph, 1996: The NCEP/NCAR 40-year reanalysis project. Bull. Amer. Meteor. Soc., 77, 437-471.

Kistler, R., E. Kalnay, W. Collins, S. Saha, G. White, J. Woollen, M. Chelliah, W. Ebisuzaki, M. Kanamitsu, V. Kousky, H. van den Dool, R. Jenne, and M. Fiorino, 2001: The NCEP-NCAR 50-year reanalysis: Monthly means CD-ROM and documentation. Bull. Amer. Meteor. Soc., 82(2), 247-267.

Kato, K., 1985: Heat budget in the atmosphere and the variation of the air temperature in the lower layer over the Okhotsk Sea (A case study during the Baiu Season in 1979). Tenki, 32, 425-433 (in Japanese).

Kawano, H., 1989: Heat and moisture budgets in the layer containing fog, stratus or stratocumulus over the sea of the southeast of Hokkaido. Tenki, 36, 369-375 (in Japanese).

Kudoh, T., 1984: Characteristics of Okhotsk air mass during the typical Yamase period (1981.6.1821). Tenki, 31, 411-419 (in Japanese).

Ninomiya, K. and H. Mizuno, 1985: Anomalously cold spell in summer over northeastern Japan caused by northeasterly wind from polar maritime airmass. Part 1. EOF analysis of temperature variation in relation to the large-scale situation causing the cold summer. J. Meteor. Soc. Japan, 63, 845-857.

_ 1987: Variations of Baiu precipitation over Japan in 1951-1980 and large-scale characteristics of wet and dry Baiu. J. Meteor. Soc. Japan, 65, 115-127.

Norris, J.R., Y. Zhang, and J.M. Wallace, 1998: Role of low clouds in summertime atmosphereocean interactions over the North Pacific. $J$. Climate, 11, 2482-2490.

Ogi, M., Y. Tachibana, F. Nishio, and M.A. Danchenkov, 2001: Does the fresh water supply from the Amur river flowing into the Sea of Okhotsk affect sea ice formation? J. Meteor. Soc. Japan, 79, 123-129.

and K. Yamazaki, 2003a: Impact of the wintertime North Atlantic Oscillation (NAO) on the summertime atmospheric circulation. Geophys. Res. Lett., 30(13), 1704, doi:10.1029/ 2003GL017280.

Ogi, M., K. Yamazaki, and Y. Tachibana, 2003b: Solar cycle modulation of the seasonal linkage of the North Atlantic Oscillation (NAO). Geophys. Res. Lett., 30(22), 2170, doi:10.1029/ 2003GL018545.

Okawa, T., 1973: Growth mechanism of the Okhotsk high. J. Meteor. Res., 25, 65-77 (in Japanese).

Parkinson, C.L., 1990: The impact of the Siberian high and Aleutian low on the sea-ice cover of the sea of Okhotsk. Ann. Glacial, 14, 226229.

Robinson, D.A., K.F. Dewey, and R.R. Heim, Jr, 1993: Global snow cover monitoring: an update. Bull. Amer. Meteor. Soc., 74, 1689-1696.

Tachibana, Y., M. Honda, and K. Takeuchi, 1996: The abrupt decrease of the sea ice over the southern part of the Sea of Okhotsk in 1989 and its relation to the recent weakening of the Aleutian low. J. Meteor. Soc. Japan, 74, 579584.

Takaya, K. and H. Nakamura, 1997: A formulation of a wave-activity flux for stationary Rossby waves on a zonally varying basic flow. Geophys. Res. Lett., 24, 2985-2988.

- 2001: A formulation of a phase-independent wave-activity flux of stationary and migratory quasi-geostrophic eddies on a zonally varying basic flow. J. Atmos. Sci., 58, 608-627.

Wang, Y., 1992: Effects of blocking anticyclones in Eurasia in the rainy season (Meiyu/Baiu season). J. Meteor. Soc. Japan, 70, 929-951. and T. Yasunari, 1994: A diagnostic analysis of the wave train propagating from highlatitudes to low-latitudes in early summer. $J$. Meteor. Soc. Japan, 72, 269-279.

Wu, B. and J. Wang, 2002: Winter Arctic Oscillation, Siberian High and East Asian winter monsoon. Geophys. Res. Lett., 29(19), 1897, doi:10.1029/ 2002GL015373.

Xie, S.-P., H. Noguchi, and S. Matsumura, 1999: A hemispheric-scale quasi-decadal oscillation and its signature in northern Japan. J. Meteor. Soc. Japan, 77, 573-582.

Yamazaki, K., 2000: Interaction between the wintertime atmospheric circulation and the variation in the sea ice extent of the Sea of Okhotsk. Seppyo, 62, 345-354 (text in Japanese, abstract and figures in English). 